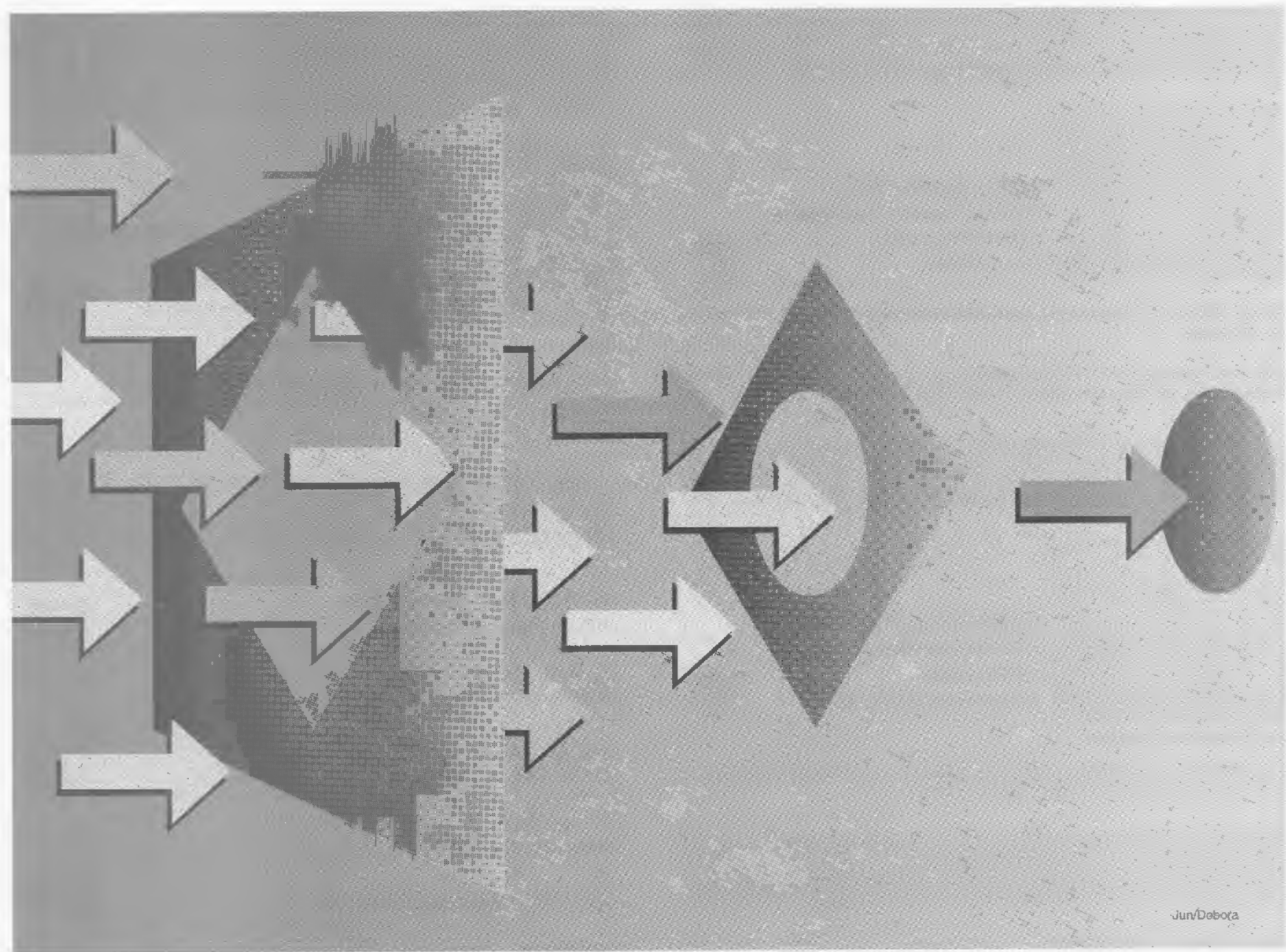

\title{
NOVA REGULAMENTAÇÃO DA TRANSFERÊNCIA DE TECNOLOGIA NO BRASIL
}

\section{José Carlos Barbieri \\ Professor do Departamento de Administração da Produção, Logistica e de Operacões Industriais e Membro do CPGT (Centro de Política e Gestão Tecnológica) da EAESP/FGV \\ Walter Delazaro \\ Professor do Departamento de Administração da Produção, Logistica e de Operações Industriais e Coordenador do NATAD (Núcleo de Assessoria Técnica e Administrativa) da EAESP/FGV.}

* RESUMO: As regulamentaçöes governamentais sobre transferência de tecnologia estäo sendo revistas em praticamente todos os paises, seguindo as políticas de abertura econômica. O propósito deste texto é discutir, para o caso brasileiro, os condicionantes e os impactos dessas modificações considerando as exigências decorrentes de um modelo de desenvoluimento baseado na competitividade internacional.
* PALAVRAS-CHAVE: Transferencia de tecnologia, novas tecnologias, política industrial e de comércio exterior, reconversão industrial, propriedade industrial.

* ABSTRACT: Government regulations on technology transfer has been revised in almost every country. These changes follow tentative policies on economic liberalization throughout the world, as presented in the paper. The proposal of the text is to discuss looking at the Brazilian case, the understandings and consequences from the proposed modifications. They will increase the requirements stablished by a development model based on international competitiveness.

* KEY WORDS: Tecnology transfer, new technologies, industrialization and foreign trade policy, industrial modernization, industrial property.

São Paulo, 33(3):6-19

Mai/Jun. 1993 


\section{INTRODUÇÃO}

A transferência de tecnologia tem sido considerada um tema importante para as políticas governamentais independentemente do grau de desenvolvimento alcançado pelos respectivos países. Questōes pertinentes a este tema continuam sendo objeto de intensa regulamentação apesar do avanço das teses liberais. Mesmo em países desenvolvidos, a intervenção governamental é uma constante, como atesta o conhecido pacto entre os Estados Unidos e o Japão para a transferência de tecnologia. Para os países em desenvolvimento, que construíram um parque industrial diversificado e de porte significativo, a ação governamental sobre a transferência de tecnologia constitui hoje uma peça fundamental para conduzir com sucesso um processo de reconversão industrial. Importantes questões dessa natureza são objetos de polêmicas acirradas, tanto no âmbito interno, quanto nas negociações intergovernamentais, como é o caso da Rodada Uruguai do GATT (General Agreement on Tariffs and Trading). Daí a necessidade de ampliar os conhecimentos sobre essa área, principalmente numa época como a atual, quando governos e organismos internacionais estão empenhados em encontrar um novo quadro institucional para as questões relacionadas com a transferência de tecnologia e a proteção dos ativos tecnológicos.

O objetivo deste trabalho é mostrar este quadro de mudanças no que concerne à transferência de tecnologia, um dos ingredientes determinantes da nova competitividade internacional. Inicialmente, será apresentada uma breve evolução da implantação do sistema de controle governamental sobre a transferência de tecnologia no Brasil e sobre as recentes mudanças que prenunciam uma nova fase de atuação do governo nesta área. Emn seguida, será apresentado um balanço cxítico desse sistema através dos resultados alcançados e das objeções que lhe foram feitas. Por fin, discutem-se as tendências internacionais e as possiveis repercussões sobre o fluxo de tecnologia do exterior para dar sustentação ao processo de reconversão industrial. Espera-se com esse trabalho contribuir para ampliar os conhecimentos sobre um tema altamente polêmico e carente de soluções pacificadas.

\section{EVOLUÇÃO DO CONTROLE GOVERNAMENTAL}

Analisando o processo de intervenção governamental sobre a importação de tecnologia pelos países em desenvolvimento ou de industrialização tardia ao longo do tempo e em escala mundial, Primo $^{1}$, que dirigiu o Registro Espanhol de Transferência de Tecnologia, de 1973 a 85 , postula uma teoria para esse processo, envolvendo quatro estágios funda-

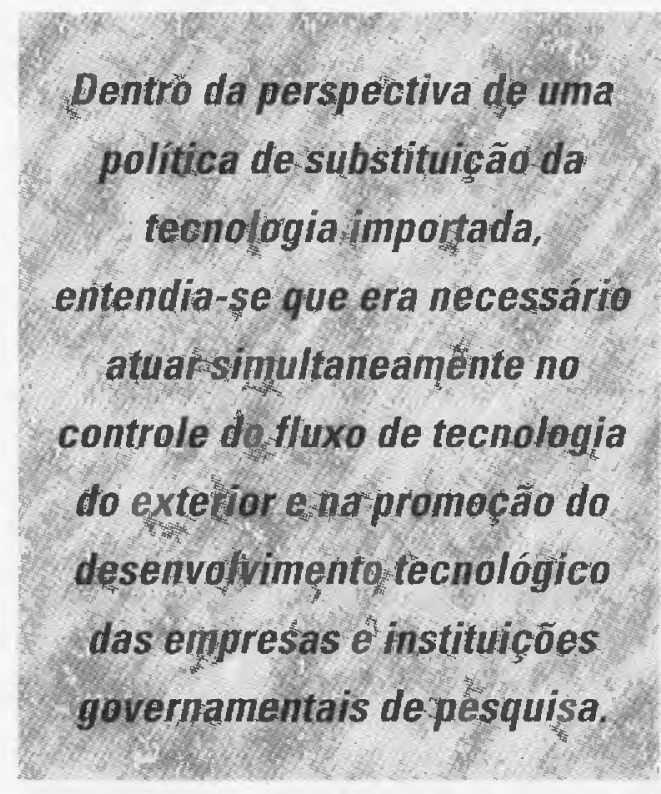

mentais. O primeiro, denominado "demanda de tecnologia", tem como objetivo básico a aquisição de tecnologia externa sem muitas considerações sobre as condições contratuais. A segunda fase, que o autor denomina de "registro dos contratos de transferência de tecnologia", surge quando já existe uma infra-estrutura técnico-cientifica e razoável produção e consumo industriais. Nesta fase, procura-se melhorar as formas e as condições com que as tecnologias são adquiridas, no sentido de eliminar cláusulas restritivas e injustas. Na terceira fase, a ênfase passa a ser o estímulo à P\&D (Pesquisa e Desenvolvimento Experimental) e à assimilação da tecnologia contratada. A supervisão e controle dos contratos passam a ser mais seletivos, procurando-se associar as compras de tecnologia com o esforço de absorção e desenvolvimento tecnológico das empresas receptoras. O último estágio seria a liberação da transferência de
1. PRIMO, Cesar. A experiência espanhola na regulamentaçāo da transferência de tecnologia. In: Informaçöes sobre Tecnologia. M!C/STI/INPI, Ano II, n. 6 , p.4, $1^{2}$ trimestre de 1986 . 
tecnologia, pela redução do controle, que passaria a ser exercido apenas nos casos em que podem ocorrer sérios abusos. Mesmo considerando que os ciclos se sobrepõem, o autor citado entende que cada um representa um patamar tecnológico mais elevado.

O esquema apresentado acima mostra que a intervenção governamental sobre a importação de tecnologia deve ser apropriada ao estágio de desenvolvimento tecnológico das empresas e do país. Quanto maior for o desnível entre estes e os supridores estrangeiros, maior será a necessidade de ação governamental para coibir abusos e direcionar as aquisições de tecnologia para os objetivos nacionais de desenvolvimento. À medida que o país desenvolve a sua capacidade técnica e científica, pode-se liberalizar os controles governamentais, pois se espera que as empresas detentoras de capacitação tecnológica própria tenham condições de realizar contratações vantajosas para si. Talvez seja este o motivo do abrandamento da legislação do Japão em anos recentes. A legislação japonesa, em matéria de transferência de tecnologia, tem sido apontada como um dos principais instrumentos que levou este país à posição de destaque que hoje ocupa, depois de sair devastado da Segunda Guerra Mundial. De acordo com Eckstrom ${ }^{2}$, o crescimento do Japão foi cuidadosamente orquestrado e conduzido pelo seu governo, através da Lei de Investimentos Estrangeiros, da Lei de Comércio Exterior e da Lei Antimonopólio, que foram sendo modificadas com o tempo em função das necessidades da indústria deste país, para permitir que as empresas japonesas pudessem ter acesso às tecnologias necessárias por meio de acordos com empresas de países altamente industrializados. Com base nessas legislações, o Japão estabeleceu um processo de importação seletiva de tecnologia, conforme as necessidades do seu setor produtivo e dos objetivos da política industrial do país. Essa legislação, no que refere-se à importação de tecnologia, foi se tornando mais liberal à medida que o país se fortalecia na produção própria de tecnologia. Após uma fase bastante restrita, que vigorou até 1968 , essa legislação foi progressivamente ampliando a liberdade de contratação de tecnologias estrangeiras sem, no entanto, eliminar completamente os mecanismos de controle governamental.

No Brasil, a intervenção governamental sobre a transferência de tecnologia também passa por fases semelhantes àquelas mencionadas acima. A primeira, que vai do pós-guerra até o início da década de 60, caracteriza-se por uma ampla liberdade para importar tecnologia com o intuito de facilitar a industrialização do país. Esta é a fase de demanda de tecnologia, suprida basicamente através da importação de tecnologia incorporada em bens de capital e nos serviços necessários a sua instalação e início de operação. Dentro dessa política, o investimento estrangeiro direto teve uma participação decisiva que marcou profundamente as características estruturais da indústria brasileira. E iria contribuir para o agravamento das crises econômicas verificadas ao final dos anos 50, quando esse processo de industrialização substitutiva de importações de bens de consumo final chegara aos seus limites. A redução do ingresso de capital estrangeiro resultante da diminuição do ritmo de industrialização ocorrido nesse período, combinada com o aumento das remessas de divisas ao exterior, produziu fortes desequilíbrios no balanço de pagamentos. Face a essa dificuldade, da qual praticamente o Brasil não iria mais se livrar, surgiram medidas governamentais de natureza fiscal e cambial para disciplinar o fluxo de recursos com o exterior, dent:e elas, medidas de controle sobre a importação de tecnologia, dando início à fase de registro dos contratos de transferência de tecnologia.

Com efeito, uma das principais medidas que procurou atuar sobre o fluxo de recursos decorrentes do pagamento por tecnologia adquirida do exterior foi a Lei 3.470 , de 1958 , de natureza exclusivamente fiscal, que, entre outras disposições, estabeleceu limites máximos à dedutibilidade no âmbito do Imposto sobre a Renda para as quantias devidas por conta de transferência de tecnologia. A Lei 4131, de 1962, que disciplina a aplicação do capital estrangeiro e as remessas de divisas ao exterior, estabeleceu pela primeira vez a obrigatoriedade do registro dos contratos de transferência de teccensing in foreing and domestic operations. New York: Clark Broardman Co., 1986. 
nologia no Banco Central, além de outros dispositivos aplicáveis a esta matéria, tal como, a proibição de pagamento de royalties pelo uso de patentes e marcas entre a filial e a sua matriz no exterior. A Lei 4.137, também de 1962, que regula a repressão ao abuso do poder econômico, abria a possibilidade de intervenção governamental para evitar cláusulas restritivas ou prejudiciais ao contratante nacional e que resultavam do seu baixo poder de barganha em relação ao fornecedor de tecnologia.

A legisłação dessa segunda fase, ou fase de registro, que vai até o final da década de 60 , previa instrumentos para eliminar cláusulas desfavoráveis ao contratante nacional, verificar o cumprimento dos objetivos contratuais e incentivar a absorção da tecnologia adquirida. Porém a intervençāo governamental sobre a importação de tecnologia perseguia basicamente as questôes fiscais e cambiais decorrentes desse comércio. No início da década de 70, essa intervenção se intensifica com a criação do INPI (Instituto Nacional da Propriedade Industrial), que passou a exercer atribuições específicas na área da transferência de tecnologia e correlatos, juntamente com as atribuições típicas de um órgão de Propriedade Industrial (Lei 5.648 de 1970). É o início da terceira fase, quando a intervençã̃o governamental sobre essa matéria se volta para estimular a absorção da tecnologia contratada e apoiar o desenvolvimento da capacitação tecnológica do país. Com isso, o controle governamental passa a ser feito em função dos aspectos tecnológicos em si e em consonância com as políticas nacionais de C\&T (Ciência e Tecnologia), sem abandonar aquelas considerações de ordem fiscal e cambial introduzidas na fase anterior.

Vale lembrar que data dessa mesma época a explicitação dessas políticas nacionais de $C \& T$, nas quais as questōes pertinentes à transferência de tecnologia sempre tiveram destaque. O I PBDCT (Primeiro Plano Básico de Desenvolvimento Científico e Tecnológico), que vigorou em 1973 e 1974, tinha entre seus objetivos o fortalecimento da capacidade de absorção e criação de tecnologia pelas empresas nacionais, públicas e privadas. O II PBDCT, do período de 1975 a 1979, estabeleceu entre os objetivos a serem al- cançados a atualização tecnológica de diversos setores, fazendo com que eles se beneficiassem de conhecimentos já existentes nos países desenvolvidos. Propunha, além disso, o fortalecimento da engenharia de projeto e da atividade consultiva, a seleção das tecnologias a serem importadas e a consolidação do sistema de propriedade industrial. O III PBDCT, estabelecido para o período de 1980 a 1985, fixava como objetivo básico a redução da dependência científica e tecnológica do país. A lógica que presidia a elaboração destas políticas e, consequientemente, dos instrumentos de controle da transferência de tecnologia era a da substituição de importação.

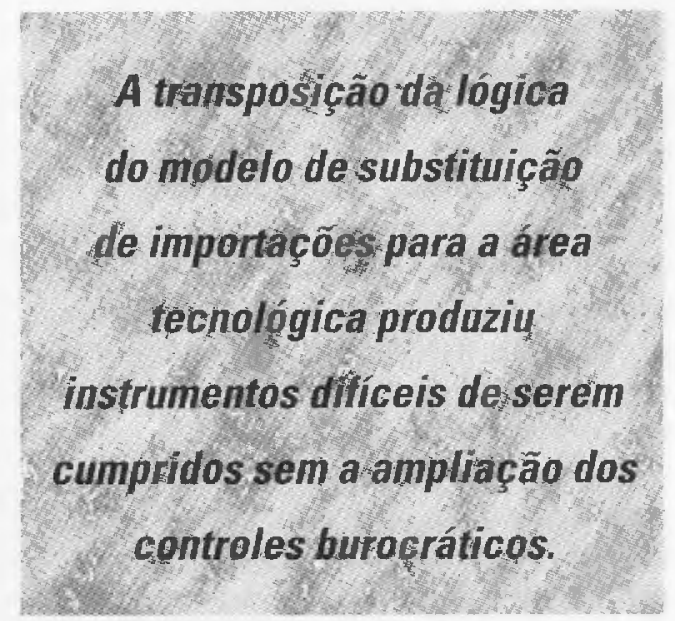

O Código da Propriedade Industrial, instituído pela Lei 5.772 de 21/12/71, fora concebido dentro de um processo de industrialização substitutiva de importações de insumos básicos, infra-estrutura industrial e tecnologia. Esse processo teve como elemento fundamental a facilidade de obter tecnologia no mercado internacional. Primeiro, por tratar-se quase sempre de tecnologias maduras, cujos investimentos feitos para obtê-las já se encontravam amortizados nos seus países de origem. Segundo, pelo isolamento da economia brasileira, próprio do modelo de substituição de importações. Os fornecedores de tecnologia nāo se sentiam ameaçados pelos receptores que, na maioria, atuavam basicamente no mercado interno. Além disso, as transações envolvendo tecnologia constituiam-se, para muitos fornecedores, na única maneira de penetrar no mercado brasileiro, altamente protegido. 
Foi tendo em vista um contexto como esse que o Código da Propriedade Industrial de 1971 estabeleceu diversos mecanismos para atuar sobre o fluxo de tecnologia do exterior, complementando outras legislações que direta ou indiretamente tratavam deste assunto, tais como a Lei $4131 / 62$ e a $4137 / 62$, já mencionadas anteriormente. Dentre os dispositivos do Código sobre essa questão, o mais importante, sem dúvida, é o que estabelece que os atos e contratos que impliquem transferência de tecnologia fiquem sujeitos à averbação no INPI (art. 126). A averbação gera importantes efeitos econômicos para o contratante local, pois é através dela que se torna possível a dedutibilidade fiscal e a legitimação dos pagamentos decorrentes. Para a empresa fornecedora, caso o objeto contratual seja patente ou marca registrada, concedida ou depositada no Brasil, a averbação constitui elemento probatório do seu uso efetivo, para impedir a extinção antecipada dos direitos por caducidade. Além desses dispositivos, o Código estabelece a proibição de remeter pagamentos por tecnologia objeto de pedido de patente em tramitação no INPI.

Inicialmente, o INPI preocupou-se com a criação e aplicação de normas regulamentatórias para efeito de averbação de contratos. Dentre estas, merecem destaque o Ato Normativo 15/75, que estabeleceu conceitos e normas para a elaboração de contratos e o Ato Normativo $32 / 78$, que criou a sistemática da consulta prévia. Posteriormente, outros Atos Normativos foram expedidos para forçar a absorção da tecnologia adquirida e incentivar a realização de atividades de pesquisa e desenvolvimento experimental (P\&D) em empresas. A partir do início da década de 80 , complementarmente, o INPI passou a criar diversos Programas e Comissões de apoio ao desenvolvimento tecnológico, como o PROFINT (Programa de Fornecimento Automático de Informações Tecnológicas), o PROATEC (Programa de Acompanhamento da Evolução Técnica da Indústria) e a Comissão Permanente para Área de Biotecnologia. Nota-se que com estes Programas o INPI procurou engajar-se de uma forma mais ativa no processo de desenvolvimento tecnológico do país, ao mesmo tempo que exercia as atribuições cartoriais que lhe são inerentes.

Durante essa terceira fase estava implícito que o controle sobre a tecnologia externa era essencial para romper o ciclo de dependência tecnológica e contribuir para o desenvolvimento autônomo do país. Dentro da perspectiva de uma política de substituição da tecnologia importada, entendia-se que era necessário atuar simultaneamente no controle do fluxo de tecnologia do exterior e na promoção do desenvolvimento tecnológico das empresas e instituições governamentais de pesquisa. Entendia-se que, sem esse controle, o empresário, pressionado por questões imediatistas, sempre iria preferir comprar tecnologia pronta a arcar com o ônus e o risco de produzir tecnologia na própria empresa, ou contratar os serviços de uma instituição de pesquisa. A fraca interação entre empresas e instituições de ensino e pesquisa, cuja superação constituía inclusive objetivo específico das políticas de C\&T, era um indício de que tal suposição estava correta.

Em meados dos anos 80, começou a se esboçar um movimento de liberação do controle em bases seletivas. Os contratos referentes aos projetos aprovados pelo PDTI (Programa de Desenvolvimento de Tecnologia Industrial) e do PSI (Programa Setorial Integral), ambos criados pelo Decreto-Lei $2.433 / 88$, que instituiu instrumentos de política industrial, passaram a ser dispensados da consulta prévia (AN 93/88). Outras medidas liberalizantes já estavam em curso no âmbito do INPI, no sentido de eliminar restrições e deixar de examinar cada cláusula do contrato, para empresas ou setores que haviam alcançado elevada capacitação tecnológica, como havia sido o caso do setor siderúrgico (Ato Normativo 99/89). As medidas adotadas pelo Executivo Federal a partir de 1990 interrompem este processo de liberalização seletiva e inauguram uma nova fase, que pretende se caracterizar por uma ampla liberalização da economia, incluindo os aspectos concernentes à transferência de tecnologia.

A nova Política Industrial e de Comércio Exterior, cujas diretrizes gerais foram aprovadas pela Portaria 365 de 26/06/90 do Ministério da Economia, Fazenda e 
Planejamento, estabeleceu como objetivo o aumento da eficiência na produção e comercialização de bens e serviços, mediante a modernização e reestruturação da indústria. Para isso, foram definidas as seguintes estratégias de ação governamental: redução progressiva dos níveis de proteção tarifária e fortalecimento dos mecanismos de defesa da concorrência; reestruturação competitiva da indústria, mediante apoio creditício e da infra-estrutura tecnológica; fortalecimento de segmentos potencialmente competitivos e do desenvolvimento de novos setores, através da maior especialização da produção; exposição planejada da indústria. brasileira à competição internacional; $\mathrm{e}$ capacitação tecnológica das empresas nacionais. Como se vê, trata-se de medidas que diferem radicalmente daquelas criadas ao longo do processo de substituição de importações. Esse documento legal menciona explicitamente o Código da Propriedade Industrial como um dos instrumentos de política industrial que deverá ser revisto.

A Comissão Interministerial instituída pela Portaria 370 de 26/06/90 para elaborar um anteprojeto de lei visando a alterar o Código da Propriedade Industrial, em relação à transferência de tecnologia, sugeriu o seguinte: desregulamentar os processo de averbação dos contratos de transferência de tecnologia; tornar facultativa a sistemática da consulta prévia; simplificar os procedimentos de análise dos contratos; explicitar que não existem limites pré-estabelecidos aos valores que serão pagos nos processos de transferência de tecnologia; e estabelecer transparência ao processo de averbação.

Em atendimento a estas recomendações, o INPI aprovou a Resoluçāo $n^{2} 22$, de $27 / 02 / 91$, que estabelece normas mais flexíveis para a averbação de contratos que impliquem transferência de tecnologia e correlatos. Essa Resolução marca o início dessa nova fase de atuação governamental sobre o fluxo de tecnologia do exterior que deverá se pautar por uma redução da intervenção governamental nesta área. A Lei 8383, de 30/12/91, que altera a legislação do Imposto sobre a Renda, revogou os dispositivos da Lei 4131/62, já comentada anteriormente, que impediam a remessa de divisas ao exterior para pagamentos de royalties entre empresas do mesmo grupo econômico (art. 50). Como essas muitas medidas liberalizantes em matéria de política industrial e de comércio exterior já estão em curso, enquanto outras aguardam as decisões no âmbito do Legislativo Federal, como é o caso das alterações no Código da Propriedade Industrial.

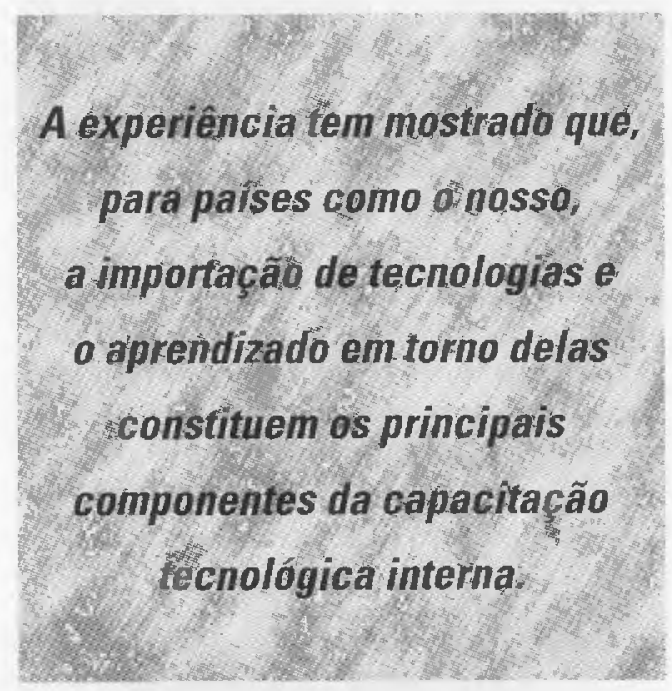

\section{RESULTADOS E OBJEÇÕES}

Não se pode negar que nessas últimas fases ocorreram excessos como, por exemplo, o Ato Normativo 65/83, que exigia do contratante nacional o levantamento prévio de documentos de patentes para justificar a contratação de tecnologia do exterior; ou a exigência feita às partes contratantes de firmar documento afirmando não possuírem entre eles outros termos acordados que não os constantes no contrato averbado. Mais ainda, o INPI utilizou de forma extensiva diversos dispositivos concernentes à dedutibilidade fiscal para servir de limites ao pagamento por tecnologia adquirida e que, em alguns casos, depois de demorados embates jurídicos, vieram a ser contrariados pela justiça. Muitas empresas deixaram de utilizar este recurso em funçāo da proverbial morosidade do nosso aparato judicial. Acrescentam-se ainda todas as disfunções de uma burocracia estatal para dar razão à grita generalizada do empresariado contra esses procedimentos de controle. 
3. UNITED NATIONS CONFERENCE ON TRADE ANO OEVELOPEMENT (UNCTAC). Control of restrictive pratices in transfer of tecnology transaction: selected principal regulation, policy guidelines and cases law at the national and regional level. New York: ONU/UNCTAD, 1982

4. KATZ, Jorge M. Importacion de tecnologia, aprendizaje e industrialización dependente. México (DF): Fondo de Cultura Económica, p. 19, 1976.
A transposição da lógica do modelo de substituição de importações para a área tecnológica produziu instrumentos difíceis de serem cumpridos sem a ampliação dos controles burocráticos. É o caso, por exemplo, do Ato Normativo 15/75 ao estabelecer que a tecnologia oriunda do exterior teria que corresponder a níveis näo existentes ou possíveis de obterem no país, apurada através do confronto com a efetiva e disponível capacitação interna para a sua execução ou com fontes alternativas já existentes (item 4.1.2). A exemplo desta, muitas outras exigências estabelecidas na regulamentação produzida nas fases anteriores procuravam aplicar o conceito de similaridade à tecnologia, à semelhança do que era feito para as mercadorias tangiveis. Isso deu ao sistema de controle da importaçăo de tecnologia um aspecto anacrônico, principalmente quando se observa o avanço das teses liberais ou neoliberais que propugnam por um Estado mínimo.

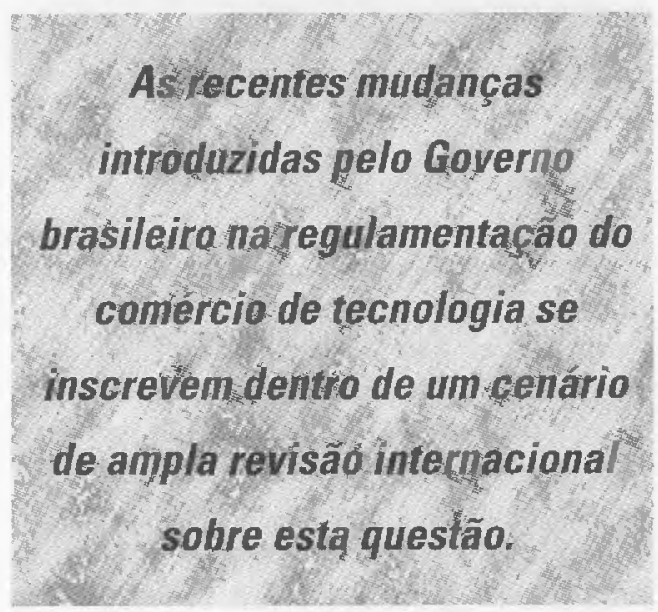

Apesar de todos os exageros cometidos não se pode deixar de reconhecer seus efeitos positivos para o desenvolvimento da capacidade tecnológica do país. Os elementos de controle instituídos ao longo das últimas fases objetivavam, de algum modo, melhorar as condições de contratação de tecnologia estrangeira e facilitar o seu domínio por parte do contratante local. Daí a preocupação com a desagregação de pacotes tecnológicos, com a fixação de limites para pagamentos, com a eliminação de cláusulas restritivas e outras condições desfavoráveis às firmas receptoras.
Vale dizer que esse tipo de preocupação ocorreu em praticamente todos os países que, a exemplo do Brasil, passaram por um processo de industrializaçâo tardia e dependente do fornecimento de tecnologia estrangeira. Vide a Decisión 24 de 1970 da Comisión del Acordo de Cartagena e a Ley sobre el Registro de la Transferencia de Tecnología, instituída no México em 1972. Na Argentina, a Lei 19.231 de 1971 estabeleceu medidas para combater as cláusulas restritivas e os pagamentos injustos e criou o Registro Nacional de Contratos de Licencia y Transferencias de Tecnología, tornando obrigatória a inscrição dos contratos para efeito de pagamentos ao exterior. Dezenas de outros países, inclusive alguns desenvolvidos, também criaram medidas para coibir as práticas restritivas no comércio de tecnologia, conforme mostra um relatório da $\mathrm{UNCTAD}^{3}$. Nas negociações multilaterais, no âmbito da UNCTAD, procurava-se elaborar um "Código Internacional de Conduta para a Transferência de Tecnologia", no qual os países não desenvolvidos, fundamentalmente importadores de tecnologia, esperavam ver incluída a condenação a todo tipo de prática abusiva neste comércio. Este Código nunca chegou a ser aprovado, dada a grande resistência dos países desenvolvidos; para os demais, eliminar essas práticas abusivas significava eliminar barreiras que impediam o desenvolvimento de uma capacitação tecnológica interna.

A experiência tem mostrado que, para países como o nosso, a importação de tecnologias e o aprendizado em torno delas constituem os principais componentes da capacitação tecnológica interna. Katz ${ }^{4}$ sustenta que uma teoria para compreender o processo de modernização técnica de países como Argentina, Brasil e México deve contemplar a existência de dois momentos distintos. $\mathrm{O}$ primeiro momento é de aquisição de tecnologia do mercado internacional e sua transferência no âmbito local. O segundo, ocorre após esta transferência e tem como fato central o aprendizado doméstico associado à adaptação do produto e do processo às condições do meio receptor, bem como da adequação deste próprio meio para incorporar a tecnologia transferida. Esse aprendizado ocorre mediante a realiza- 
ção de serviços técnicos do tipo troubleshooting para solucionar problemas da fábrica, da engenharia do produto e do processo e de outras atividades técnicas que permitem absorver e assimilar a tecnologia importada. A esses, pode-se acrescentar um terceiro momento, quando o país passa a produzir internamente parte dos componentes tecnológicos necessários à implementação de inovações significativas através da realização de P\&D original, engenharia de projeto etc.

Um estudo realizado por Fleury ${ }^{5} \mathrm{com}$ empresas do setor mecânico, incluindo pequenas, médias e grandes, revelou que a capacitação tecnológica destas empresas ocorreu dentro de um processo de aprendizado orientado para a produção, no qual a funçäo Engenharia cumpre um papel fundamental. O autor parte da 'véia de que, para a empresa, a tecnologia se apresenta como um "pacote de informações organizadas, de diferentes tipos (cientificos, empiricos etc.), provenientes de várias fontes (descobertas cientificas, patentes, livros, manuais etc.), e através de diferentes métodos (pesquisa, desenvolvimento, adaptação, reprodução, espionagem)", conforme definem Sábato \& Mackenzie $^{6}$. Assim, para Fleury 7 , aprendizado tecnológico é um processo evolutivo, no qual a empresa passa a criar e desenvolver sua capacidade em produzir pacotes, tendo como principal fonte de informação as atividades de produção. A partir de pacotes obtidos inicialmente mediante licenciamento ou cópia, a empresa aprende a produzir outros para contar com processos mais eficientes e produtos de melhor qualidade. Trabalhos realizados por $\mathrm{Kin}^{8} \mathrm{e} \mathrm{Lall}^{9} \mathrm{na}$ Índia e Coréia do Sul, respectivamente, mostram que o mesmo tipo de aprendizado também se deu nestes países. Kin sugere que o ciclo completo de aprendizado envolve as fases de implementação da tecnologia importada, assimilação e melhoramentos; Lall denomina estas fases de aprendizado elementar, intermediário e avançado. Esse processo de aprendizado evolutivo provavelmente não se daria de modo pleno sem a atuação governamental sobre as condições de aquisição e absorção das tecnologias importadas.

Näo há dados sobre as tecnologias que năo ingressaram no país por causa do controle exercido pelo governo. Certamente muitas negociações não se concretizaram por esse motivo, porém, não é correto atribuir a esse controle a redução do fluxo de tecnologia do exterior. Como mostra a tabela 1 , as remessas ao exterior por importação de tecnologia decresceram ao longo da década de 80 , chegando em 1988 a menos da metade do que fora no final da década de 70, uma época marcada pela extrema rigidez do INPI. Uma das causas desse fato encontra-se na recessão econômica do início dos anos $80 \mathrm{e}$ a redução dos investimentos durante toda esta década. Dados do IBRE/FGV 10 mostram que a formação bruta de capital fixo, que na década de 70 alcançara em média $22,4 \%$ do PIB, cai sistematicamente na década de 80 , chegando a $16 \%$ no seu final, que, na opiniäo desta instituição, trata-se de um percentual insuficiente para o retorno do crescimento econômico às taxas históricas.

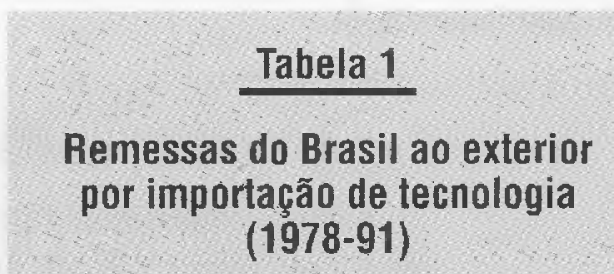

\begin{tabular}{|c|c|c|c|}
\hline ANO & $\begin{array}{c}\text { USS } \\
\text { (Milhües) }\end{array}$ & ANO & $\begin{array}{l}\text { USS } \\
\text { (Milinties) }\end{array}$ \\
\hline 1978 & 231 & 4985 & 175 \\
\hline 1979 & 313 & 1986 & 184 \\
\hline 1980 & 321 & 1987 & 193 \\
\hline 1981 & 276 & 1988 & 141 \\
\hline 1982 & 254 & 1989 & 169 \\
\hline 1983 & 218 & 1990 & 187 \\
\hline 1984 & 202 & 1991 & - \\
\hline
\end{tabular}

Fonte: Relatórios do Banco Central do Brasil: 1981 p.99, 1983 p.82, 1986 p.89, 1987 p. 117,1991 p. 97.

A tabela 2 mostra o movimento de averbação de contratos de Serviços Técnicos Especializados, categoria contratual que representou cerca de $66 \%$ do total de contratos de tecnologia averbados no pe-
5. FLEURY Afonso. Gestão de tecnologia na empresa indus trial brasileira. Revista de Administraçăo. São Paulo, v. 22, n 4. p. 3-13 (p.4), out./dez. 1987.

6. SÁBATO, JOrge, A MAKENZIE, M. Tecnologia e estrutura produtiva. São Paulo: IPT, n 20,1981 (publicações especiais).

\section{FLEURY, Afonso. Op. cit.}

8. KIN, Linsu. Stages of developement of industrial technology in a developing country: a model. Research Policy. North-Holland, v.9, n. 1, p. 154-77, jan 1980.

9. LALL, Sanjaya. Developing countries as exporters of industrial tecnology. Research Policy. North-Holland, v. 9, n. 1, p. 2452, jan. 1980.

10. INSTITUTO BRASILEIRO DE ECONOMIA DA FUNDACĀO GETÚLIO VARGAS (IBRE/FGV). Carta do IBRE: como sair da estagnação. Conjuntura Econômica, v. 42 , n. 11, p. 7-10, jan 1988. 
ríodo considerado. Os contratos envolvendo Serviços de Engenharia de Montagem Industrial, uma das suas subcategorias, apresentaram um declínio significativo nesse período, principalmente em meados dos anos 80, tanto em percentual, quanto em valor contratado. Esses dados refletem, sem dúvida, uma redução do ritmo de implantação de novas unidades produtivas, bem como da renovação das plantas e equipamentos industriais existentes. Refletem também o aprendizado obtido internamente pelas empresas nacionais de engenharia que, por força da regulamentação estabelecida em 1980 , passaram a ser obrigatoriamente as contratantes principais desses serviços, a menos que as empresas usuárias demonstrassem possuir, em caráter permanente, técnicos em quantidade e especialidades suficientes para absorver a tecnologia objeto da contratação (A to Normativo $60 / 80$ ). A redução do valor médio dos contratos, como mostra a tabela 2 , é um indicador desse aprendizado induzido pela regulamentação.

\section{TENDÊNCIAS INTERNACIONAIS}

As recentes mudanças introduzidas pelo Governo brasileiro na regulamentação do comércio de tecnologia se inscrevem dentro de um cenário de ampla revisão internacional sobre esta questão. $\mathrm{O}$ ambiente internacional apresenta-se altamente competitivo, onde as novas tecnologias desempenham um papel fundamental na reestruturação dos setores produtivos; e a ampliação do processo de oligopolização em nível internacional estabelece novas formas de cooperação e competição entre grupos econômicos, com vistas a repartir o mercado mundial. Tudo isso acompanhado de práticas protecionistas, principalmente no que concerne à transferência de tecnologia. Nos foros internacionais, os governos dos países desenvolvidos têm proposto medidas que objetivam, simultaneamente, ampliar a liberdade de circulação de mercadorias e serviços e restringir a difusão de tecnologia, quer pela ampliação dos direitos do titular de pa-

\section{Tabela 2}

\section{Contratos averbados pelo INPI de serviços técnicos especializados (STE) na área de montagem industrial}

\begin{tabular}{|c|c|c|c|}
\hline ANO & $\begin{array}{l}\text { NQ.DE } \\
\text { CONTRATOS }\end{array}$ & $\begin{array}{c}\text { VALOR } \\
\text { TOTAL } \\
\text { USS MILHOES }\end{array}$ & $\begin{array}{l}\text { VALOR } \\
\text { MEDIO } \\
\text { uss MIL }\end{array}$ \\
\hline 1979 & 983 & 517,5 & 526,5 \\
\hline 1980 & 909 & 294,0 & 323,4 \\
\hline 1981 & 905 & 284,9 & 314,8 \\
\hline 1982 & 737 & 333,4 & 452,3 \\
\hline 1983 & 562 & 186,5 & 331,8 \\
\hline 1984 & 395 & 178,8 & 452,6 \\
\hline 1985 & 383. & 95,7 & 249,8 \\
\hline 1986 & 506 & 86,6 & 171,1 \\
\hline 1987 & 549 & 98,5 & 179,4 \\
\hline 1988 & 642 & 153,0 & 238,3 \\
\hline 1989 & 619 & 179,8 & 289,9 \\
\hline 1990 & 627 & 145,8 & 232,5 \\
\hline 1991 & 501 & & - \\
\hline
\end{tabular}

MONTAGEM INDUSTRIAL.

\begin{tabular}{ccc}
\hline $\begin{array}{c}\text { No. DE } \\
\text { CONTRATOS }\end{array}$ & $\begin{array}{c}\text { VALOR } \\
\text { TOTAL } \\
\text { USS MILHOES }\end{array}$ & $\begin{array}{c}\% \text { SOBRE } \\
\text { TOTAL } \\
\text { DE STE }\end{array}$ \\
\hline 342 & 236,5 & 35 \\
\hline 321 & 93,9 & 35 \\
\hline 346 & 108,5 & 48 \\
\hline 282 & 153,3 & 38 \\
\hline 158 & 24,6 & 28 \\
\hline 70 & 16,8 & 18 \\
\hline 85 & 24,6 & 22 \\
\hline 54 & 16,0 & 11 \\
\hline 79 & 20,6 & 14 \\
\hline 93 & 23,1 & 14 \\
\hline 95 & 18,3 & 15 \\
\hline- & - & - \\
\hline- & - & - \\
\hline
\end{tabular}

Fonte: INPI/Diretoria de Contratos. - Divișão de Estudos e Estalisticas. 
tentes, quer pelo reconhecimento das práticas restritivas no comércio de tecnologia.

Na Rodada Uruguai de negociações multilaterais do GATT, iniciada em 1986, os países industrializados ricos defendem propostas que tornariam os sistemas de proteção da propriedade intelectual (patentes, marcas, know how, mask work etc.) mais rigorosos e inflexíveis, retirando dos países a possibilidade de legislar unilateralmente sobre esta matéria, segundo suas conveniências. Na avaliação dos países industrializados, os acordos intergovernamentais existentes, principalmente a Convenção da União de Paris para a Proteção da Propriedade Industrial, estabelecem princípios de proteção muito flexíveis, que favorecem a criação de sistemas nacionais de proteçăo aos ativos tecnológicos pouco eficazes. Dessa forma, os governos desses países defendem a inclusão desse tema na esfera das negociações no âmbito do GATT, tema esse que até então tivera como foro privilegiado a OMPI (Organização Mundial da Propriedade Intelectual). A mudança de foro para essa questão implica o abandono de uma regulamentação internacional formada por adesões voluntárias, como são os tratados administrados pela OMPI, para um tratamento de caráter impositivo, típico do GATT, com dispositivos mais eficazes para obrigar os países a cumprir as cláusulas acordadas, tal como, o uso de retaliações comerciais.

Além disso, os países ricos defendem a ampliação dos direitos resultantes das atividades científicas e tecnológicas, tais como: aumento dos prazos de validade para as patentes; redução da descrição da invenção (disclosure) para efeito de patenteamento; proteção aos segredos de comércio (trade secrets); proibiçăo da possibilidade dos países de excluir setores econômicos ou áreas tecnológicas da proteção patentária; eliminação dos dispositivos legais que obrigam a exploração da patente concedida no país concedente, como é o caso da licença obrigatória estabelecida na Convenção da União de Paris; e, como já foi dito, o uso de mecanismos punitivos, como a retaliação comercial, aos países que permitirem infrações aos direitos de propriedade intelectual.
Medidas como essas modificam completamente o modo de apropriação de conhecimentos tecnológicos. Uma delas, a eliminação da exigência de full disclosure como condição para a concessão de patentes, rompe com uma das principais justificativas que acompanhou a introdução dos sistemas de patentes desde a sua origem no início da Era Moderna, qual seja, a de que a patente promove a disseminação de informações científicas e tecnológicas, pois ela torna pública a inven-

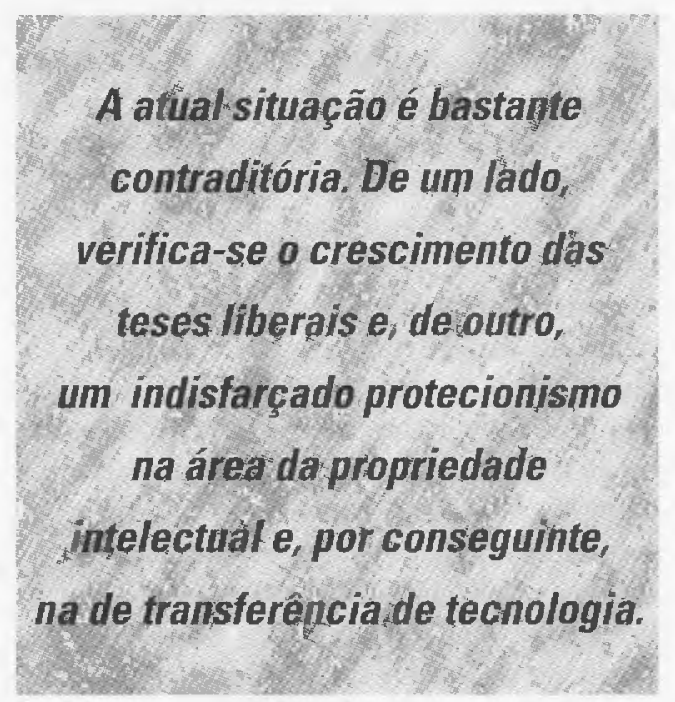

ção ou modelo patenteado. Assim, para a sociedade, a patente seria preferivel ao sigilo como modo de proteção de conhecimentos aplicáveis aos sistemas produtivos. Para os países de industrialização tardia a redução do disclosure tornará mais diff́cil o uso das informações contidas na documentação resultante do processo de patenteamento para fins de desenvolvimento tecnológico interno. Vale dizer que a utilização dessa documentação para esta finalidade era recomendada por organizações como OMPI, UNIDO (União das Naçōes Unidas para o Desenvolvimento Industrial) e UNCTAD (Conferência das Nações Unidas para o Comércio e o Desenvolvimento), como parte das estratégias de desenvolvimento tecnológico do tipo cathing up. Entendia-se que a possibilidade de usar tais informações constituía uma das poucas vantagens que os países tecnologicamente atrasados poderiam obter da sua adesão aos tratados internacionais sobre propriedade industrial. 
11. GONDA, Roberto U. La nueva ley mexicana en matéria de propriedade industrial. Comércio Exterior, México (DF), v. 21 n. 11, p. 1057, nov. 1991.

12. PATEL, Surendra J. Los derechos de propriedad intelectual em la Ronda de Uruguay. $\mathrm{Co}$ mércio Exterior, México (DF), v. 39 n. 4 , p. 288-301 (p. 299), abr. 1989.

13. CORREA, Carlos Maria. Proteccionismo tecnológico y acceso a tecnologia en los paises en desarrolo. In: SEMINÁRIO INTERNACIONAL: TRANSFERÊNCIA DE TECNOLOGIA E MUDANÇA NO CENÁRIO INTERNACIONAL (mimeo). São Paulo, $p$. 2, 20-22 de novembro de 1990.

14. CARDOZO, Arthur Câmara Consideracione sobre el tema de la protección tecnológica y los paises em desrrolo. In: Reflexiones de caracas: taller de especialistas in política tecnológica. Anais. Caracas: UNCTAD, p. 77,4 a 8 de junio de 1990 .

15. ZYSMAN, John. Trade, Tecnology and national competition. Internation Journal of Tecnology Management, v. 7, n.1, jan. 1992.
Mesmo que tais propostas ainda não tenham sido aprovadas pelo GATT, muitos países já começaram a introduzi-las em suas legislações de propriedade industrial, em atendimento às pressões, via comércio exterior, praticadas pelos países desenvolvidos, principalmente os Estados Unidos. A legislação de comércio exterior deste país, modificada em 1984, prevê a possibilidade de estabelecer retaliações comerciais contra países que não ofereçam proteção eficiente aos direitos de propriedade Intelectual (U. S. Trade and Tariff Act, seção 301 e Omnibus Trade and Competitiveness $A c t$, super 301). Face às pressões dessa natureza, diversos países já revisaram suas leis de propriedade intelectual $\mathbf{e}$ de transferência de tecnologia, como é o caso do México, que veio modificando sua legislação desde 1986, culminando com a "Ley de Formento y Proteción de La Propriedad Industrial“ de 1991. De acordo com Gonda ${ }^{11}$, esta nova Lei, que aumentou consideravelmente os direitos dos titulares de patentes e marcas, acompanha uma tendência mundial que já está presente nas legislações de vários países, dentre eles, Coréia do Sul, Espanha, Canadá, Bélgica, Chile e China. No Brasil, a proposta de alteração do Código da Propriedade Industrial (Lei 5772/71), em tramitação no Legislativo Federal, também se inscreve nesta tendência geral de fortalecimento dos direitos dos titulares de patentes, tais como a ampliação dos seus prazos de validade e das áreas possíveis de patenteabilidade (produtos químicos de per $s e$, produtos e processos farmacêuticos, alimentícios etc).

A atual situação é bastante contraditória. De um lado, verifica-se o crescimento das teses liberais e, de outro, um indisfarçado protecionismo na área da propriedade intelectual e, por conseguinte, na de transferência de tecnologia. Ou, como ironiza Patel ${ }^{12}$, esses governos "advogam ao mesmo tempo a liberdade para seus comerciantes e a proteção para os seus industriais". Na opinião de Correa ${ }^{13}$, a ofensiva dos países industrializados nessa área reclamando por mais proteção à propriedade intelectual e ao seu comércio deve-se às seguintes razões:

1. a intensificação das atividades de P\&D e a elevação dos seus custos;
2. maiores dificuldades de apropriação das novas tecnologias;

\section{3. a globalização do mercado mundial;}

4. o acirramento da competição internacional e o declínio da liderança dos Estados Unidos.

Para Cardozo ${ }^{14}$, a perda de competitividade desse país tem sido vista como o resultado de um modelo de proteção demasiado aberto e, portanto, incapaz de impedir que outros países pudessem eventualmente se beneficiar da sua tecnologia, aproveitando-se de fragmentos de informações que viessem a ter acesso. Diversos autores, tal como Zysman ${ }^{15}$, utilizam a expressão "neo-mercantilismo" para caracterizar essa nova postura altamente intervencionista dos governos dos países tecnologicamente avançados em torno do desenvolvimento tecnológico e de suas novas formas de proteção. Nada mais distante do liberalismo pretendido para o comércio de mercadorias tangíveis e para o fluxo de capitais.

As ações concretas entre as empresas produtoras de tecnologias já incorporaram as práticas protecionistas objeto das negociações da Rodada Uruguai. As aquisições de tecnologia pela via contratual exclusiva e isolada, que prevaleceram até meados da década passada, estão sendo rapidamente substituídas por acordos globais entre empresas para formar alianças estratégicas, envolvendo mercados, tecnologias, composição societária, fontes de financiamento etc. Essas alianças pressupõem formas mais complexas de interação entre empresas, tais como joint venture, projetos conjunto de $\mathrm{P} \& \mathrm{D}$ e licenças cruzadas (cross-licensing) para uso de patentes, marcas e know how, formando um relacionamento de cooperação e competição simultâneo. As alianças estratégicas refletem o aprofundamento de uma tendência do comércio de tecnologia desde há muito conhecida, qual seja, a de ser este comércio mais propício para operações casadas, na qual cada empresa passa a ser, ao mesmo tempo, fornecedora e receptora de tecnologia. Assim, a empresa que produz tecnologia de modo sistemático adquire maior facilida- 
de para contratar tecnologias de outras. Essas aquisições recíprocas baseiam-se na impossibilidade de se alcançar a excelência tecnológica pulverizando recursos em diversas áreas técnicas e neutralizam a tendência de encarecimento de P\&D, conforme já mencionado. De fato, em muitos casos analisados por Berg et al. ${ }^{16}$ a joint venture reduziu a intensidade de P\&D, ao nível das empresas, bem como os riscos e o tempo para introduzir o novo produto ou processo no mercado. Além disso, as alianças tornam mais eficazes os instrumentos de apropriaçăo dos conhecimentos tecnológicos, como a patente e o sigilo, à medida que criam vínculos mais estreitos entre as empresas envolvidas, pois, na qualidade de fornecedoras e receptoras recíprocas, transformam-se em parceiras para explorar novos negócios. Por isso, os acordos globais entre empresas com capacitações tecnológicas semelhantes deverão prevalecer cada vez mais tomando-se as formas dominantes de transferências de tecnologias relevantes. Contrariamente, os acordos isolados entre empresas com grandes desniveis tecnológicos tendem a diminuir com o tempo, ou ficar restritos às tecnologias maduras ou defasadas em relação ao estado da arte do setor onde elas se aplicam. Os acordos globais são formas de transações coerentes com a era de globalização da economia, da formação de blocos econômicos e dos programas e consórcios de desenvolvimentos tecnológicos cooperativos, como é o caso do programa ESPRIT (European Strategic Program for $R \& D$ in Information Technology), ou do "Semiconductor Research Corporation", um consórcio formado por mais de 20 empresas norteamericanas para financiar atividades de P\&D em áreas do seu interesse a serem realizadas por instituiçŏes de ensino e pesquisa.

problema agora é ter acesso às novas tecnologias, acesso este cada vez mais restrito. Não faz mais sentido aqueles instrumentos de controle concebidos para uma realidade completamente diversa, quando não mais se verificam aquelas facilidades para importar tecnologia que prevaleceu durante o processo de substituição de importações. No momento, verifica-se uma verdadeira con- tração no comércio internacional de tecnologia, como decorrência de uma economia cada vez mais globalizada e do desenvolvimento das novas tecnologias. Estas, como fontes de produtividade e de competitividade internacionais não se encontram disponíveis com a mesma facilidade das tecnologias maduras. As exigências por parte dos fornecedores tornaram-se muito maiores. Impor limites estreitos ao pagamento de tecnologia, obrigar o fornecedor a aceitar a interve-

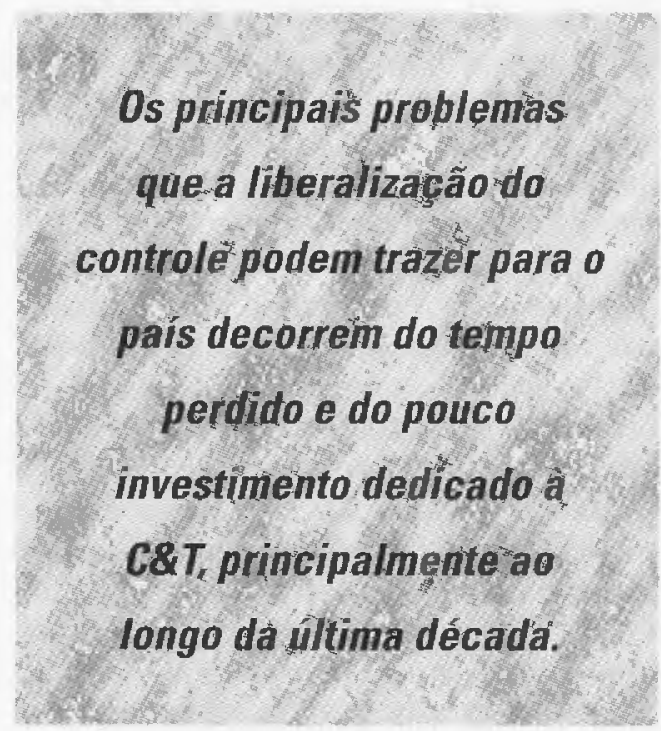

niência de instituição governamental de pesquisa para ajudar a receptora a absorver a tecnologia adquirida, e outros expedientes semelhantes utilizados pelo INPI já não fazem sentido neste novo cenário internacional. Além disso, dada a abertura do mercado interno, é de se esperar que os fornecedores de tecnologia, a continuar os procedimentos de controle, prefiram eles mesmos investir no país ou abastecer o mercado através de importaçōes, a transferir tecnologia. Assim, parece salutar as recentes medidas adotadas pelo Governo brasileiro, embora o mais correto seria acelerar o processo de liberalização seletiva que já vinha ocorrendo desde o final da década passada.

Esta năo é uma situação exclusiva do Brasil. Praticamente todos os países estão adequando suas legislações a essa nova configuração do mercado internacional de tecnologia. Por exemplo, no México a nova "Lei sobre el Control y Registro de Transferencia de Tecnología y el Uso y
16. BERG, Sanford V.: DUNCAN, Jerome; FRIEDMAN, Philip. Joint venture strategies and corporate innovation. Cambridge, Mass: Gunn \& Hain Publishers Inc., p. 127-35, 1982. 
17. SOBERANIS, Jaime Álvares. La política mexicana em matéria de transpaso tecnológico. Comércio Exterior, México, D.F., v 40 , n. 8, p. 767-772, ago. 1990.

18. CORREA, Carlos Maria.Tecnologia y desarrolo de la informática en el contexto norte-sur. Buenos Aires: Eudeba, p. 96-7, 1989.

19. BARRAZA, Juan Antonio Toledo. Justificaciones de política industrial y comercial para abrogar la ley de tranterência de tecnologia. Comércio Exterior México (DF), v. 41, n. 11, p. 1037-1040, nov. 1991.

20. CONSELHO NACIONAL DE DESENVOLVIMENTO CIENTÍFICO E TECNOLÓGICO (CNPq). Orçamento da União para a C\&T. Brasilia, CNPa, p. 10 , 1989
Explotación de Patentes y Marcas", de 1990, reduziu a intervenção governamental nessa área a tal ponto que, na opinião de Soberanis ${ }^{17}$, o registro dos atos e contratos sobre transferência de tecnologia no órgão competente converteu-se praticamente num requisito formal.

\section{PROBLEMAS E PROMESSAS}

Com o afrouxamento da intervenção governamental sobre o comércio de tecnologia, pode-se vislumbrar de pronto alguns problemas. Operações fictícias envolvendo transferência de tecnologia podem servir como fachada para remessas disfarçadas de lucro ou para qualquer outra finalidade deste gênero. Vale lembrar que isso de certa forma já ocorreu na Argentina. Este país começou a disciplinar essa matéria em 1971 com a criação do "Registro Nacional de Contratos de Licencia y Transferencia de Tecnología", que passou a funcionar dentro do INTI (Instituto Nacional de Tecnologia Industrial), e com o estabelecimento de normas gerais para a efetivação dos registros. Em 1976, com a ditadura militar, inicia-se uma mudança de orientação política, com a adoção de medidas liberalizantes em matéria econômica, incluindo as que referem-se à transferência de tecnologia. Em 1977, a atuação do INTI nesta questão ficou limitada apenas ao registro informativo dos contratos, que, em outras palavras, significou eliminar as exigências prévias para efetuar as contratações, conforme eram feitas até aquela data. De acordo com Correa ${ }^{18}$, as remessas a título de pagamento por tecnologia saltaram de US\$ 51 milhões em 1977, o ano da mudança, para US\$ 484 milhões, ao final desse processo de liberalização em 1983. Nesse mesmo período, ocorria na Argentina um desmantelamento da sua estrutura produtiva, especialmente do setor industrial, acompanhado de uma queda de $17 \%$ do PIB. Ou seja, ao contrário do que seria de esperar, o aumento dos pagamentos ao exterior por tecnologia não tiveram nenhuma correlação com o crescimento econômico do país.

O que ocorreu na Argentina mostra que a liberalização do comércio internacional de tecnologia pode trazer distor- ções para os países que ainda continuam dependentes economicamente e, por conseguinte, em matéria de tecnologia. Estas distorções serão tanto maiores quanto maiores forem os seus desajustes econômicos. Barraza ${ }^{19}$ mostra que no México a principal preocupação quanto à liberalização do comércio de tecnologia, estabelecido em 1991, conforme mencionado na seção anterior, referia-se à possibilidade de ocorrer uma avalanche de modificações nos contratos existentes para incluir restrições antes não toleradas, inclusive elevação dos pagamentos. Isso porém não ocorreu, pelo menos nos primeiros meses dessa nova regulamentação, e os pagamentos de royalties ficaram entre 4 a $7 \%$ do preço de venda, taxas essas semelhantes às praticadas no período anterior à liberalização. $\mathrm{Na}$ opinião desse autor, esses dados mostram que as empresas nacionais que contrataram tecnologia, seja com fornecedores locais, seja com estrangeiros, haviam aprendido a negociar e que a experiência acumulada de 18 anos de regulamentação dessa matéria produziu resultados favoráveis.

Os principais problemas que a liberalização do controle podem trazer para o país decorrem do tempo perdido e do pouco investimento dedicado à $C \& T$, principalmente ao longo da última década. Neste aspecto, o Brasil se encontra numa posição de clara desvantagem em relação aos seus principais parceiros no comércio internacional, face a um desenvolvimento tecnológico que ao longo do tempo se mostrou descontínuo e aquém do que seria necessário para promover a transição de um modelo econômico fechado para outro baseado na competição internacional, competição que se mostra cada vez mais acirrada.

No Brasil, os investimentos em C\&T também ficaram estagnados, como mostra o orçamento da União para a Ciência e Tecnologia (OUCT) ao longo dos anos. Dados levantados pelo $\mathrm{CNPq}^{20}$ mostram que, de 1981 a 1988, o OUCT/PIB passou de $0,38 \%$ a $0,42 \%$ respectivamente, o que representa um acréscimo insignificante para um país que almeja superar a dependência tecnológica conforme estabelecia os PBDCTs, já comentados. Considerando que o OUCT corresponde a 
aproximadamente $2 / 3$ dos dispêndios totais em C\&T, verifica-se que o país investiu em torno de $0,63 \%$ do PIB nestas áreas. Este percentual provavelmente não deve ser muito maior no momento, em decorrência do descaso com que essa área foi tratada a partir de 1988, mas principalmente nesses primeiros anos da década atual. Trata-se, portanto, de recursos insuficientes para reduzir o hia to tecnológico que separa o Brasil do mundo desenvolvido, onde os dispêndios em C\&T freqüentemente alcançam percentuais superiores a $2,5 \%$ do PIB. Dentro da lógica que orienta o mercado internacional de tecnologia, um país ou empresa que investe pouco em tecnologia, passa a ter dificuldades para adquirir tecnologias relevantes, principalmente quando se observa a escalada do protecionismo ou, como querem alguns, do "neomercantilismo", nessa área. Assim, sem que esse cenário interno se altere, a ampliação das medidas liberalizantes poderão gerar efeitos adversos para a economia brasileira, podendo-se antever mais uma década perdida, ou década dolorosa, como preferiria dizer Fajnzylber ${ }^{21}$.

\section{CONCLUSÃO}

A experiência internacional mostra que a intervenção governamental sobre a importação de tecnologia deve ser apropriada ao estágio de desenvolvimento das empresas e do país. Quanto maior for o desnível entre estes e os fornecedores estrangeiros, maior será a necessidade de ação governamental para coibir as aquisições contrárias aos objetivos de desenvolvimento do país. À medida que o país desenvolve a sua capacidade técnica e científica, pode-se proceder a uma gradual e seletiva liberalização dos controles governamentais, pois espera-se que as empresas que possuam capacitação tecnológica própria tenham condições de realizar contratações vantajosas para si, sem a necessidade de serem tuteladas pelo governo.

O Brasil passou por diversas fases da atuação governamental nesta área, evoluindo desde uma liberdade absoluta, com o objetivo de promover a industrialização em marcha acelerada, até a institui- ção de controles rígidos, com o objetivo de melhorar as condiçōes e forçar o processo de absorção da tecnologia importada. Ao final, esse sistema de controle buscava uma liberalização seletiva, como que premiando empresas e setores que haviam se envolvido com esforços próprios para se capacitarem tecnologicamente. A década de 90 começa com uma liberalização que só não é absoluta porque muitas medidas restritivas ainda estão em vigor, dependendo de alterações no âmbito do Poder Legislativo. São os casos, por exemplo, das alterações no Código da Propriedade Industrial e na legislação que disciplina o capital estrangeiro.

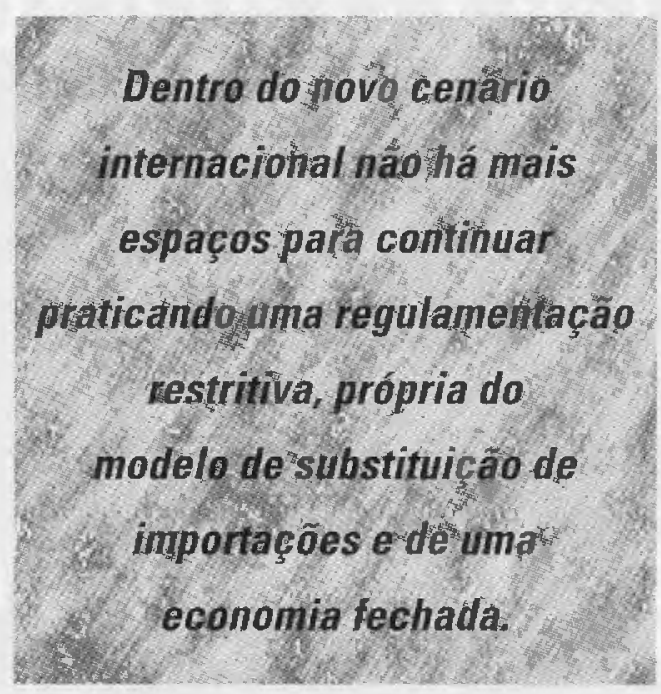

Hoje, o Brasil vive uma situação bastante difícil. Dentro do novo cenário internacional não há mais espaços para continuar praticando uma regulamentação restritiva, própria do modelo de substituição de importações e de uma economia fechada. Porém, a abertura que está sendo feita e que pressupõe um modelo competitivo de reconversão industrial, encontra a economia enfraquecida pela crise prolongada, pelos planos de estabilização fracassados e pela profunda recessão deste início de década. Acrescenta-se a isso a lamentável situação em que se encontra a área de C\&T, como decorrência de anos de políticas desastradas e irresponsáveis. Sem a reversão desse cenário desfavorável, os benefícios esperados da liberalização do comércio de tecnologia podem não se concretizar.
21. FAJNZYLBER, Fernando Inserción internacional e innovación institucional. Revista de la CEPAL, Santiago (CH), p. 167, ago. 1991. 